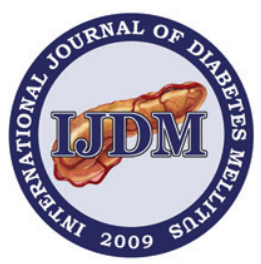

Diabetes Science International

International Journal of Diabetes Mellitus

www.elsevier.com/locate/ijdm

www.sciencedirect.com

ORIGINAL ARTICLE

\title{
Efficiency of co-expression of transcription factors Pdx1, Ngn3, NeuroD and Pax6 with insulin: A statistical approach
}

\author{
Don F. du Toit a , Benjamin Longo-Mbenza ${ }^{\text {b }}$, Benedict J. Page a \\ Venant Tchokonte-Nana ${ }^{\text {a,* }}$
}

${ }^{a}$ Department of Biomedical Sciences, Division of Anatomy and Histology, University of Stellenbosch, South Africa

${ }^{\mathrm{b}}$ Faculty of Health Sciences, School of Medicine, Walter Sisulu University, South Africa

Received 15 September 2010; accepted 24 January 2011

\section{KEYWORDS \\ Efficiency; \\ Islets; \\ Co-expression; \\ Insulin; \\ Transplantation}

\begin{abstract}
Aim: The objective of this study was to investigate the time related profile and efficiency of co-expression of the homeodomain proteins Pdx1, NeuroD, Ngn3, Pax6 and caspase3 with insulin, and to establish the time periods post PDL optimum for islets transplantation.

Study design/methods: In this experimental study, immunofluorescent staining procedure was performed on deparaffinized pancreatic duct ligated (PDL) tissues of 78 Sprague-Dawley rats. Quantification of protein coexpression was made using a computerized morphometry. The efficiency of co-expression was arbitrary defined by the value of mean ratio (score without unit) of insulin expression divided by each expression index of the other proteins, occurring within the time interval of 12-24 h post PDL. Statistical tool was used to analyze the efficiency of co-expression of proteins; analysis of variances (one way ANOVA) was used to compare the means of co-expression indexes across the time periods pre- and post PDL. $P$-values less than 0.05 were considered statistically significant; no post hoc test was done.

Results: The curve of insulin expression showed a crossover with that of the co-expression at
\end{abstract}

\footnotetext{
* Corresponding author. Tel.: + 27 (0)790374141; fax: + 27 (0) 866 964744.

E-mail addresses: dfdt@iafrica.com (D.F.du Toit), longombenza@ yahoo.fr (B. Longo-Mbenza), bjp@sun.ac.za (B.J. Page), venant@, sun.ac.za (V. Tchokonte-Nana).
}

1877-5934 @ 2011 International Journal of Diabetes Mellitus. Published by Elsevier Ltd. All rights reserved. doi:10.1016/j.ijdm.2011.01.007

\begin{tabular}{|l|l|}
\hline \\
ELSEVIER
\end{tabular}


different time periods pre- and post PDL. The optimal or higher efficiency of co-expression was observed for insulin and Ngn3 co-expression, while a good or medium efficiency was noted for the co-expression of insulin with Pdx1, insulin with NeuroD and insulin with Pax6. Low or weak efficiency was observed for the co-expression of insulin with caspase 3 .

Conclusion: We therefore propose an early islets transplantation using $12-24 \mathrm{~h}$ post PDL harvested pancreatic tissues.

(C) 2011 International Journal of Diabetes Mellitus. Published by Elsevier Ltd. All rights reserved.

\section{Introduction}

The mammalian pancreas derives from the foregut endoderm. Early differentiation from endodermal cells into endocrine cells forming the pancreatic islets of Langerhans is significantly determined by a cascade of genes activation event $[1,2]$. During foetal time, the clusters of epithelial cells in the embryonic phase differentiate into the mature endocrine cells of the islets of Langerhans, the duct cells, and the exocrine cells $[3,4]$.

The chronobiology of these differentiated cells is well known: the glucagon-expressing alpha cells are followed by insulin-producing beta cells, somatostatin-producing delta cells and pancreatic polypeptide-producing PP cells $[5,6]$. Reliable data suggest that protein encoded by some of class $\mathrm{B}$ bHLH genes such as neurogenin $3(\mathrm{Ngn} 3)$ and NeuroD are interrelated [7], and expressed in an overlapping and redundant manner [8,9]. Ngn3 is required for endocrine fate determination in the developing mouse pancreas [10]. The proposed position for the transcription factors Pdx1, Ngn3, Pax6 and insulin is based on the timing (chronobiology) of individual protein expression $[1,11,12]$.

As diabetes mellitus (DM) is now a global epidemic, it afflicts around 300 million patients worldwide [13], shifting from developed countries towards developing countries, including sub-Saharan countries [14]. Studies dealing with pancreas development at the molecular level are urgently needed. These studies may be involved in providing cues and potential tools for in vitro generation of functional beta-cells from stem cells after the pancreatic duct ligation (PDL), despite existing controversies in post PDL pancreatic atrophy [15], and remarkable increase in mass of the survived islets [16]. However, the chronobiology of co-expression of Pdx1, Ngn3, NeuroD and Pax6 homeodomain proteins is not known, although there are evident suggestions that transcription factors may be involved in the proliferation of the islet after pancreatic duct ligation [17,18]. The research question was raised as follows: what time before $84 \mathrm{~h}$ after PDL might be the best moment to release the duct ligation, or to perform pancreatic transplantation, according to protein co-expression in the rats? Indeed, the autogenous transplantation of PDL tissue in the kidney of diabetic rats performed at $84 \mathrm{~h}$ following individual expression of insulin showed a graft failure in $50 \%$ of the animal group [19].

Thus, this study aims to investigate the time-related profile and efficiency of the co-expression of homeodomain proteins Pdx1, NeuroD, Ngn3, Pax6, and caspase3 with insulin; and to establish the time periods post PDL optimum for islets transplantation.

\section{Materials and methods}

\subsection{Laboratory animals}

Seventy-eight male, randomly selected healthy SpragueDawley rats were obtained from the Central Animal Unit of the Faculty of Health Sciences, University of Stellenbosch. The rats were weighed and put into groups of six animals each, corresponding to the time periods post-PDL of $6,12,24,36$, 48, 60, 72, 84, 96, 108 and $120 \mathrm{~h}$, and time periods pre-PDL of 0 and $5 \mathrm{~h}$ at which animals were killed. While animals in both groups pre-PDL $0 \mathrm{~h}$ and $5 \mathrm{~h}$ did not undergo duct ligation, animals in group pre-PDL $5 \mathrm{~h}$ had the abdomen opened and closed only (sham operation).

\subsection{Pancreatic duct ligation}

A fully equipped microsurgery laboratory at the Department of Anatomy and Histology was used for the PDL surgical procedure. A night prior to PDL, the rats were housed in clean cages and in a thermally controlled environment with free access to water but no food.

On the day of the surgical procedure, induction of anaesthesia was achieved by $5 \%$ halothane vaporized in $\mathrm{O}_{2}$, such that there was no spontaneous movement and no withdrawal responses to tail or foot pinch. Abdominal hair was shaved using a surgical blade, one centimetre on either side of the linea alba to avoid excessive heat loss. Great care was taken not to abrade or cut the skin. The shaved portion of the abdominal surface was then cleaned with betadine antiseptic solution containing providone-iodine at $10 \mathrm{mg} / \mathrm{ml}$ (Adcock Ingram Pharmaceuticals, Industria, Johannesburg, RSA).

The animals were placed on their back (dorsal recumbency); the hind limbs were maintained on the surgical table by means of a paper tape with a minimum tension, to avoid muscle strains. A mid-line laparotomy incision, starting from the tip of the xiphoid process to about one centimetre above the pelvic symphysis, was made to obtain access to the abdominal cavity. The stomach and the duodenum were drawn out and reflected cranially, to expose the pancreas. The topographical position of the pancreas was noted, and cotton buds were used to prise the pancreas away from the surrounding tissue. A Zeiss OPMI-1 operating microscope equipped with a zoom and a focus adjustment (Carl Zeiss, AG, Oberkochen, Germany) aided in identifying the colourless pancreatic duct. A resorbable suture material $(5 / 0$ sterile white braided silicone treated polyester, USP, Davis and Geck, Isando, South Africa) soaked in saline solution, was used for a tight single suture occluding duct, made at about $1 / 3$ proximal to the tail end 


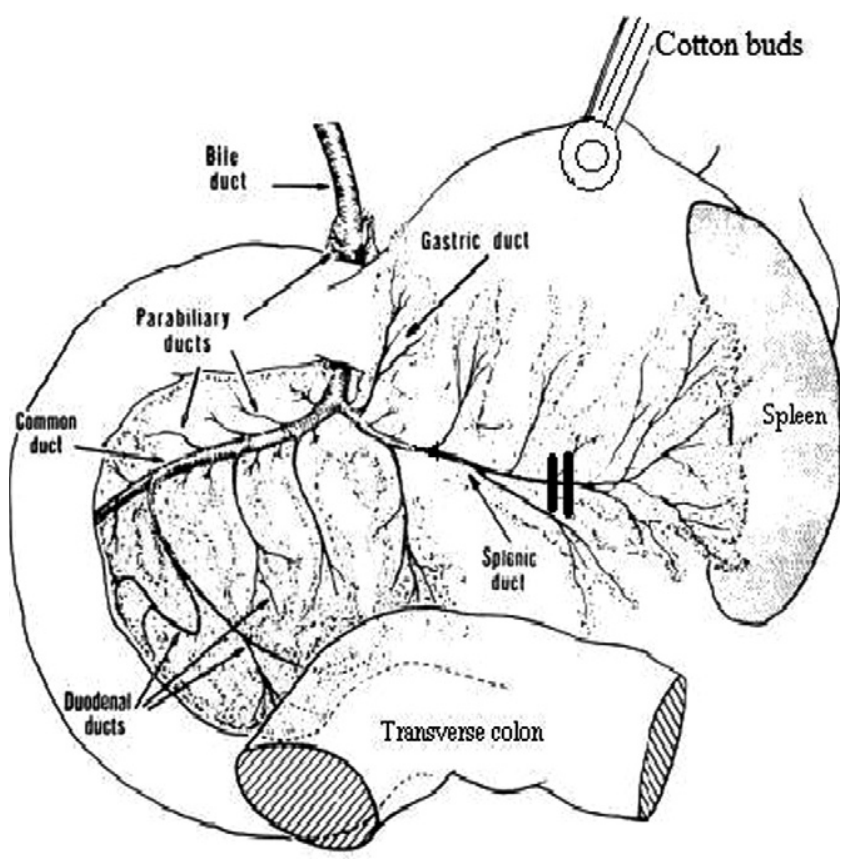

Figure 1 The pancreas of the laboratory rat is prised away to expose the point of ligation (double bold line) in the splenic lobe.

of the pancreas (splenic lobe) (Fig. 1). Care was taken to avoid damage to the underlying blood vessels.

After ligation, $5 \mathrm{ml}$ of warm saline solution was introduced into the abdominal cavity, to prevent the post PDL dehydration. The laparotomy incision was closed in two separate layers of a continuous (blanket) stitching using 5/0 sterile white braided silicone treated polyester (Davis and Geck, Isando, South Africa); first the peritoneum together with the abdominal muscles were sutured and the skin followed thereafter, the whole procedure taking approximately $10 \mathrm{~min}$. A subcutaneous injection of $2.5 \mathrm{mg}$ of Amoxil (Smith-Kline Beecham Pharmaceuticals, Midrand, RSA) and $0.5 \mathrm{mg}$ streptomycin (NovoStrep $5 \mathrm{~g} / 15 \mathrm{ml}$, Novo Nordish (Pty) Ltd., Johannesburg, RSA) was administered as a single subcutaneous dose at the scruff of the neck to guard against infection; the wound was then swabbed with an antiseptic rub (Beige Pharmaceuticals Pty. Ltd., Edenvale, South Africa) to minimize scratching. Animals were returned to clean laboratory rodent cages under a $60 \mathrm{~W}$ lamp necessary for rapid recovery and to counter hypothermia, and were housed in a thermally controlled environment with free access to water and standard rat chow (Epol, Midrand, RSA) until they were killed. The effects of the post procedural treatment regimens, which might impact on the recapitulation process of endocrine cells development were not considered and remain an unknown parameter in this study.

\subsection{Tissue removal and processing}

On the day of tissue collection corresponding to time periods pre- and post PDL, animals were anaesthetised as described earlier; placed in a dorsal recumbence, the hind limbs were maintained on the surgical table by means of a paper tape, and a mid-line laparotomy incision was made along the previ- ous incision, to gain access to the abdominal cavity. The stomach and the duodenum were drawn out and reflected cranially to expose the pancreas. The post-ligature portion of the pancreas was surgically isolated and removed after the surrounding blood vessels had been ligated. The animals were then euthanized by introducing $200 \mathrm{mg} / \mathrm{kg}$ sodium pentobarbitone into the abdominal cavity and the carcases disposed of by incineration.

The isolated portions of the pancreas were excised $(5 \times 5 \mathrm{~mm})$ and placed in labelled tubes containing Bouin's fluids for tissue preservation. Approximately 6-18 h later, postligature fixed-portions of the pancreas were placed in labelled plastic cassettes, and were processed through a standard histology routine. The PDL tissues were then embedded in paraffin wax (at $55^{\circ} \mathrm{C}$ ), and the resulting tissue blocks were kept at room temperature $\left(20-25^{\circ} \mathrm{C}\right)$ until sectioning took place.

\subsection{Immunochemical markers}

The choice for the markers to label the homeodomain proteins (Pdx1, Ngn3, NeuroD and Pax6) involved in endocrine pancreas development was based on the hierarchy in the time related expressions of the transcription factors. ${ }^{1}$ The markers used as primary antibodies were the markers for endocrine pancreas development genes and cellular apoptosis (caspase3) both polyclonal and raised in rabbit, and the monoclonal marker for Beta cells (insulin) raised in mouse. However, Dichloro Triazinyl Amino Fluorescein (FITC) and Cyanine-3 (Cy3) were used as secondary antibodies; both have a duallabel fluorescent incorporated compound and were goat anti-Rabbit $\mathrm{IgG}$ and goat anti-mouse $\mathrm{IgG}$, respectively. The markers (primary antibodies and secondary antibodies) were purchased from CHEMICON International Inc., (Bellerica, USA).

\subsection{Double-label immunofluorescence}

Prior to the immunofluorescent procedure, an electric autoclave at $1000 \mathrm{~W}$ was used to retrieve the antigenicity of tissues by heating. Plastic racks carrying deparaffinised tissue sections was immersed into the autoclave container filled with $100 \mathrm{ml}$ pre-treatment solution of $10 \mathrm{mM}$ citrate buffer $(\mathrm{pH}$ 6.0); the autoclave was switch on until temperate reached $100{ }^{\circ} \mathrm{C}$ in about $5 \mathrm{~min}$. Slides were maintained in boiling pre-treatment solution for further $15 \mathrm{~min}$, when the container was taken off the autoclave and slides were allowed to cool in the pretreatment solution for $20 \mathrm{~min}$ at room temperature before immunostaining took place.

A parallel approach of immunofluorescence dual labeling (PIFD), was used as follows: Sections were immersed in a working bufferl for $3 \mathrm{~min}$ and sections were incubated for $30 \mathrm{~min}$ with $10 \mu \mathrm{l}$ of a mixture of the two primary antibodies (raised from different species, mouse and rabbit) solution at appropriate respective working dilutions. Sections were rinsed in working buffer 1 for $3 \mathrm{~min}$ and subsequently incubated with $10 \mu \mathrm{l}$ in a mixture of two secondary antibodies FITC and Cy3 at a dilution of 1:200 for $30 \mathrm{~min}$. Sections were washed in

\footnotetext{
${ }^{1}$ Our study focussed on a number of transcription factors that have been shown by Schwitzgebel et al. [1] to be involved in endocrine pancreas development in a specific time-related pattern.
} 
$0.05 \%$ Tween 20 in PBS for 3 min and were finally rinse in distilled water for $3 \mathrm{~min}$; sections were counterstained and cover slipped as described earlier. After staining was completed, slides were stored in dark at $4{ }^{\circ} \mathrm{C}$ until viewed.

A fluorescent nuclear dye 4',6-diamidino-2-phenylindole (DAPI) with an antifade solution was used as counterstain to labelled cell nuclei.

\subsection{Quantification of the co-expression of proteins in PDL pancreas}

The protein expression in tissues were determined by the fluorescence emissions obtained from positive labelled cells; the resulting images were acquired by the Zeiss colour camera with the exposure time processed identically under a multidimensional image acquisition module of Axiovision 4.8 (Imaging System, Carl Zeiss; München, Germany) driven by a computerized system. The FITC-labelled cells were excited at $490 \mathrm{~nm}$ and emitted green (at $520 \mathrm{~nm}$ ), while Cy3-labelled cells were excited at $456 \mathrm{~nm}$ and emitted red (562 nm); all counterstained DAPI-labelled nuclei were excited at $365 \mathrm{~nm}$ and emitted blue $(463 \mathrm{~nm})$. The captured images accurately represent the visual impression of the observer.

The digital images were segmented and the features of the positive labelled cells were programmed using the automeasurment software of Axiovision 4.8 and MTB2004 configuration (both Carl Zeiss Vision $\mathrm{GmbH}$ ). All the images to analyse were given a name (image name) and the features of measurements were set as regions and field features as described below:

- The regions consisted of each labelled cell (count) and the area of the individual labelled cell (area).

- The field feature consisted of the total number of labelled cells (total count) expressed $n$, the total area of labelled cell (total sum) expressed in $\mu \mathrm{m}^{2}$ and the expression index.

The number of fluorescent labelled cells for the same antigen were counted and their cell surface areas measured by automation. Data were recorded per time post PDL for each immunofluorescence procedure and saved automatically in files.

\section{Definitions}

The landmarks in targeting the expression profile of homeodomain proteins involved in the remodelling of the pancreas after surgical duct ligation were determined by the morphological changes observed under $\mathrm{H} \& \mathrm{E}$ slides of the post ligation portion of the pancreas during the time periods post-pancreatic ligation (PDL). These landmarks were used in the analysis of expression patterns of transcription factors following the quantification of protein expressions at each period of time pre- and post PDL. The resulting expression of individual homeodomain proteins and their co-expression with insulin defined the lineage of endocrine cell development in the duct ligation pancreas in the laboratory rat.

The expression index, which is essentially in quantifying the protein expression in all the tissue sections in each group, was calculated using the following formula:

Expression index $=$ total number of count/total area
Dual gene expression (co-expression) of different homeodomain proteins with insulin was expressed as a ratio of the expression index of insulin per the expression index of each one of the proteins across the time period pre- and post PDL. The co-expression of insulin and other homeodomain proteins was defined by a curve parallel to the curve of insulin expression index across the time period pre- and post PDL.

The efficiency (highest and earliest expression) of co-expression was arbitrarily defined by the value of mean ratio (score without unit) of insulin expression divided by each expression of the other proteins, occurring within the time interval of 12 $24 \mathrm{~h}$ post PDL. Levels of ratio of co-expression were said to be optimal or high $(>25)$, good or medium (20-25), and low or weak $(>20)$.

\subsection{Ethical issues}

Ethical approval was obtained from the University of Stellenbosch Ethics Committee with reference number P04/01/ 001. This study complies with the recommendations of the Declaration and the guiding principles laid down by Animal Welfare Organization and the Society for the Prevention of Cruelty to Animals (SPCA).

\subsection{Statistical analysis and Immunohistofluorescence evaluation}

Continuous variables were expressed as mean \pm standard deviation (SD) or standard error of mean (SEM). To analyse individual homeodomain protein expression and the efficiency of coexpression of proteins, analysis of variances (one-way ANOVA) was used to compare the means of protein expression indices across the different time periods pre- and post-PDL. Simple coefficient of correlation " $r$ " was calculated to assess potential associations between the different protein expression indices in the study. $P$-values less than 0.05 were considered statistically significant; no post hoc test was done. Data were exported from MS Excel (Microsoft Inc., USA) to the Statistical Package for Social Sciences (SPSS) version 15 for Window (SPSS Inc., Chicago, IL, USA) for statistical analysis.

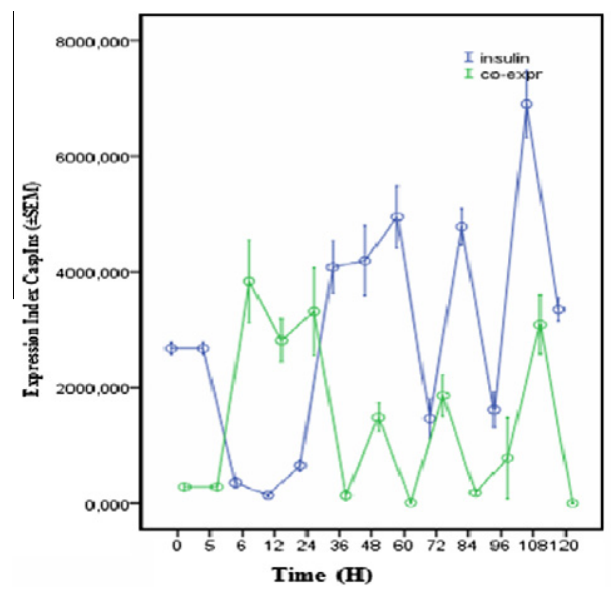

Figure 2a Dual expression index insulin in blue and caspase 3 in green across the period of times pre- and post-PDL. 


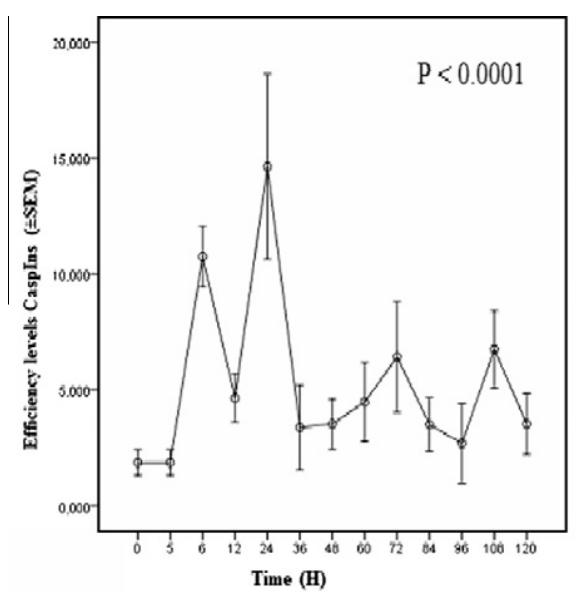

Figure 2b Efficiency levels of insulin and caspase3 gene coexpression across the period of times pre- and post-PDL.

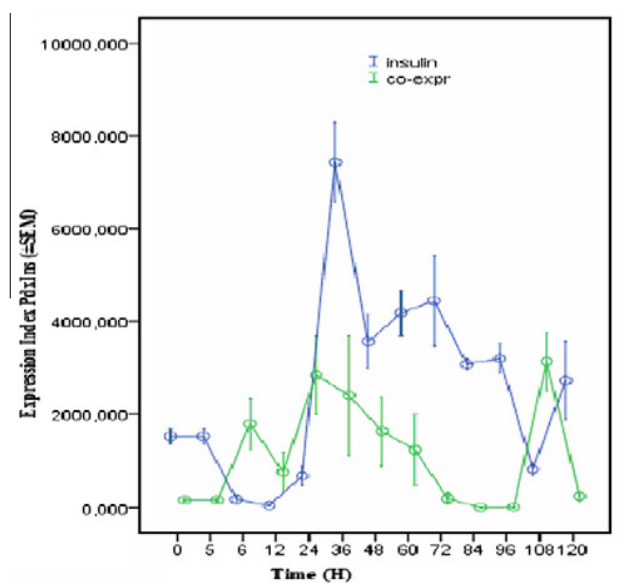

Figure 2c Dual expression index of insulin in blue and Pdx1 in green across the period of times pre- and post-PDL.

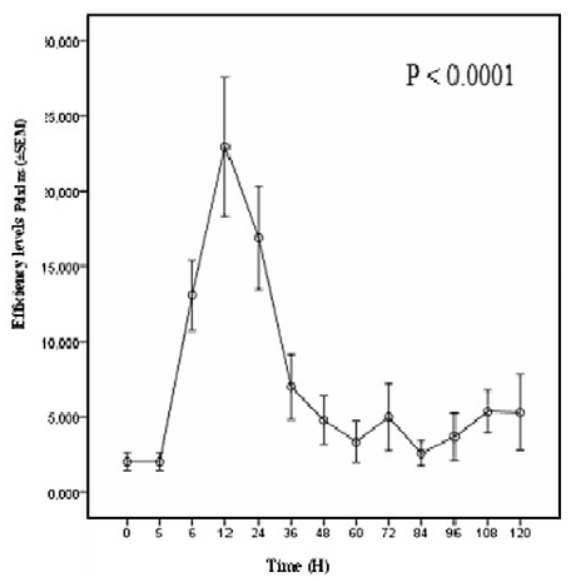

Figure 2d Efficiency levels of insulin and Pdx1 co-expression across the period of times pre- and post-PDL.

\section{Results}

\subsection{Co-expression of insulin with caspase3}

Fig. 2a shows the mean expression index of insulin and that of the co-expression (insulin-caspase3) as covariate. The highest mean expression index of the co-expression occurred between 6 and $24 \mathrm{~h}$ post PDL, whereas the highest expression index of insulin occurred later, at $108 \mathrm{~h}$ post PDL.

The efficiency curve in Fig. $2 b$ represents the co-expression index of insulin with caspase 3 . It shows four modes at $6 \mathrm{~h}$, $24 \mathrm{~h}, 72 \mathrm{~h}$ and $108 \mathrm{~h}$ post-PDL. There was a highly statistical difference (ANOVA; P > 0.0001) of its mean values between all the time periods pre- and post-PDL. The highest mean level of efficiency was $24 \mathrm{~h}$ post PDL; however, the variability of efficiency was very high at the same time.

\subsection{Co-expression of insulin with $P d x 1$}

The highest mean expression index of insulin was observed at $36 \mathrm{~h}$ post $\mathrm{PDL}$, while the highest peaks of the co-expression in-

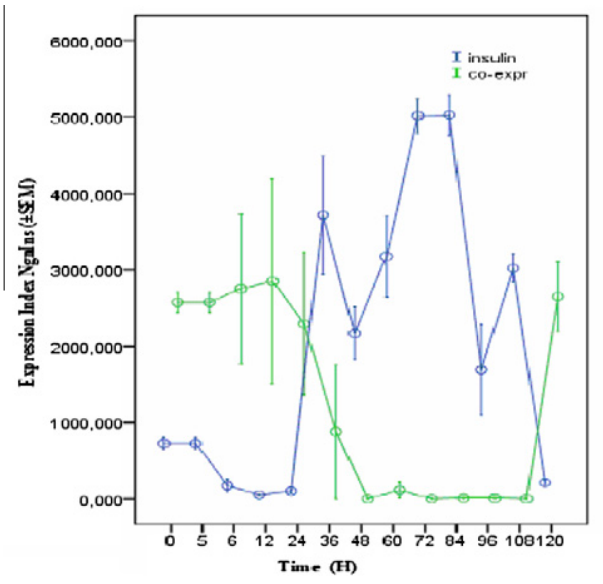

Figure 3a Dual expression index of insulin in blue and Ngn3 in green across the period of times pre- and post-PDL.

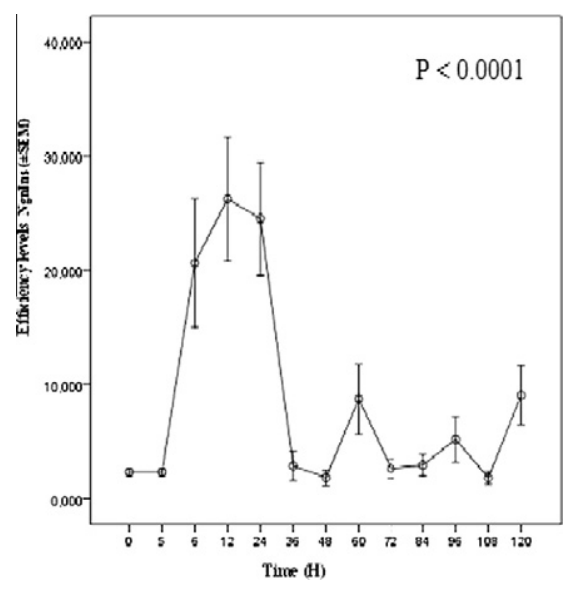

Figure 3b Efficiency levels of insulin and Ngn3 co-expression across the period of times pre- and post-PDL. 


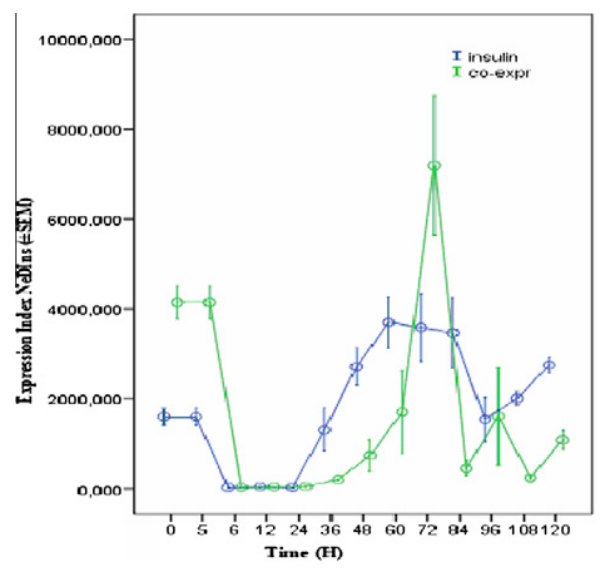

Figure 3c Dual expression index of insulin in blue and NeuroD in green across the period of times pre- and post-PDL.

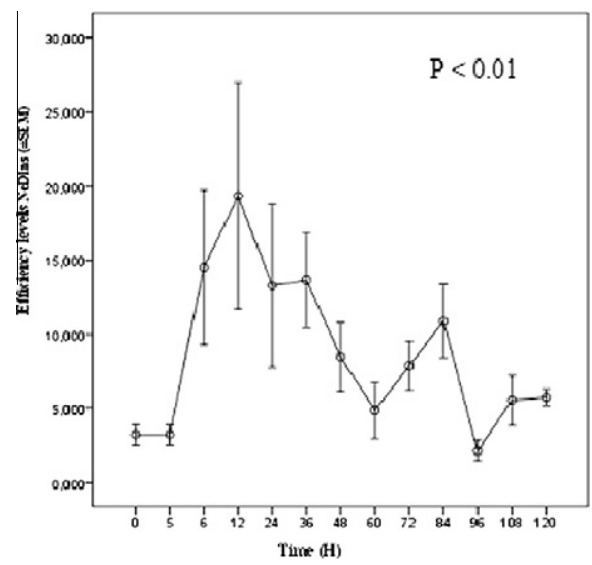

Figure 3d Efficiency levels of insulin and NeuroD across the period of times pre- and post-PDL.

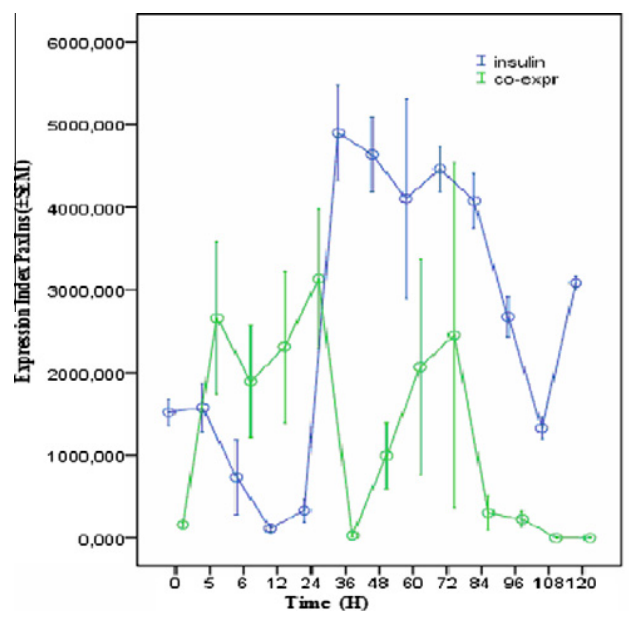

Figure 4a Dual expression index of insulin in blue and Pax6 in green across the period of times pre- and post-PDL.

dex of insulin with Pdx 1 were successively observed at $24 \mathrm{~h}$ and $108 \mathrm{~h}$ post PDL (Fig. 2c).

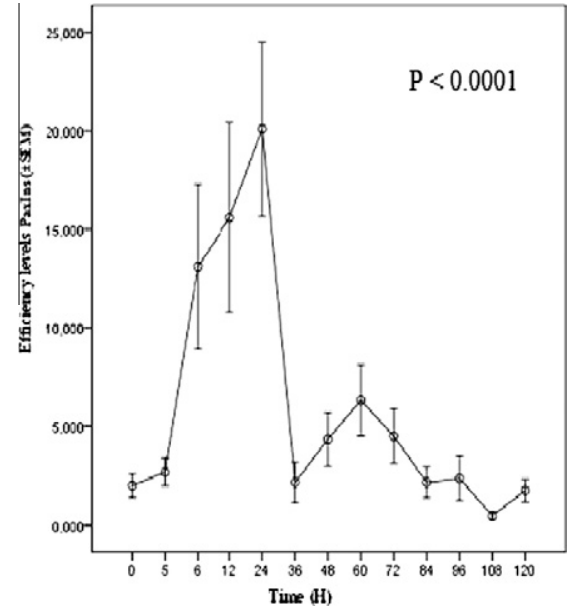

Figure 4b Efficiency levels of insulin and pax6 co-expression across the period of times pre- and post-PDL.

Table 1 Different levels of efficiency of proteins co-expressed with insulin.

\begin{tabular}{lll}
\hline $\begin{array}{l}\text { Co-expressed } \\
\text { proteins }\end{array}$ & $\begin{array}{l}\text { Means } \pm \mathrm{SD} \\
\text { of ratio }\end{array}$ & $\begin{array}{l}\text { Times concurrent } \\
\text { with higher ratio (h) }\end{array}$ \\
\hline Ins/Casp3 & $15 \pm 2.5$ & 24 \\
Ins/Pdx1 & $24 \pm 11.9$ & 12 \\
Ins/Ngn3 & $27 \pm 18.8$ & 12 \\
Ins/NeuroD & $20 \pm 26.5$ & 12 \\
Ins/Pax6 & $20 \pm 16.7$ & 24 \\
\hline
\end{tabular}

The efficiency level of co-expression of insulin with Pdx 1 was characterized by a uni-modal curve with a peak at $36 \mathrm{~h}$ (Fig. 2d). This peak was defined by higher variability. There was a significant difference (ANOVA; $P>0.0001$ ) between all the times periods pre- and post PDL.

\subsection{Co-expression of insulin with Ngn3}

The highest mean levels of expression index of insulin occurred between $72 \mathrm{~h}$ and $84 \mathrm{~h}$ post PDL, whereas the highest peaks of co-expression of insulin with Ngn3 were successively observed at $12 \mathrm{~h}$ and $120 \mathrm{~h}$ post PDL (Fig. 3a).

Fig. $3 b$ depicts the mean efficiency levels of insulin and Ngn3 co-expression. The highest level of efficiency was concurrent, at $12 \mathrm{~h}$. A significant difference (ANOVA; $P>0.0001$ ) was observed between the time periods post-PDL.

\subsection{Co-expression of insulin with NeuroD}

The curve of co-expression index of insulin and NeuroD was dominant in comparison with that of insulin expression at the time periods 0 and $6 \mathrm{~h}$ and later between 60 and $84 \mathrm{~h}$ with an overshoot observed at $72 \mathrm{~h}$ post PDL. This contrasted with the plateau mode of insulin expression between $60 \mathrm{~h}$ and $84 \mathrm{~h}$ post PDL (Fig. 3c).

However, the mean efficiency levels of insulin and NeuroD co-expression reached a highest peak at $12 \mathrm{~h}$ (Fig. 3d). A higher variability of efficiency was observed at 6-24 h. There was a 
significant difference (ANOVA; $P=0.007$ ) of efficiency mean values between the time periods pre- and post-PDL.

\subsection{Co-expression of insulin with Pax6}

The highest mean of the co-expression index of insulin and Pax6 was observed at $12 \mathrm{~h}$ post PDL, whereas the expression of insulin was totally dominant over that of the co-expression with a plateau mode between $36 \mathrm{~h}$ and $84 \mathrm{~h}$ (Fig. 4a).

The mean efficiency levels of insulin and Pax6 co-expression reached a highest peak at $24 \mathrm{~h}$ (Fig. 4b). There was a significant difference (ANOVA; $P>0.0001$ ) of mean values between the time periods post-PDL.

\subsection{Comparison of efficiency levels in protein co-expression}

Table 1 compares the levels of efficiency for the various homeodomain protein co-expressions with insulin. There was a significant difference of efficiency levels across the proteins involved in the study (ANOVA; $P<0.05$ ).

The optimal or high efficiency of co-expression was observed for insulin and Ngn3 co-expression, while a good or medium efficiency was for the co-expression of insulin with Pdx1, insulin with NeuroD and insulin with Pax6. Weak or low efficiency was observed for insulin and caspase 3 coexpression.

\section{Discussion}

The present study assessed the dual expression of various homeodomain proteins implicated in the endocrine pancreas development during the time periods post PDL. Thus, the profile, the variations, the intercorrelations and the efficiency of insulin, caspase 3, Pdx1, Ngn3, NeuroD and Pax6 were investigated in PDL model of laboratory rats. This was necessary to understand the chronobiology of expression of these proteins in order to determine the optimum time periods for islets transplantation.

\subsection{Insulin expression and its variations when co-expressed with other proteins}

The highest expression of insulin in this study was observed at $84 \mathrm{~h}$ post PDL; the same time was observed in the immunofluorescent evaluation. There was a significant and positive correlation between Ngn3, Pax6 and insulin expression. This is logical as insulin expression requires a mature endocrine beta cell development [1]. Previously, it was revealed that early insulin-expressing cells have low insulin levels [20] and these cells do not co-express transcription factor Pdx1 [21,22]. This is demonstrated by the low levels of insulin expression in the first mode of the insulin expression curve in this study.

When insulin was expressed at the same time with the other assessed, the efficiency of co-expression was observed between insulin and Ngn3 (optimal or high efficiency); insulin with Pdx1, insulin with NeuroD and insulin with Pax6 (good or medium efficiency) and insulin with caspase 3 (low or weak efficiency). Indeed the highest efficiency of co-expression of insulin with Pdx 1, Ngn3 and NeuroD occurred at $12 \mathrm{~h}$ post PDL. These findings confirmed the dependency of the islet of Lan- gerhans development on the sequential cascade of transcription factors activation phases [2]. The highest efficiency of co-expression of insulin with Pax6 occurred differently at $24 \mathrm{~h}$, and probably may be due to the extent and span of Pax6 function throughout the endocrine development until the endocrine cells reach maturity $[4,11,23,24]$.

Furthermore, the morphological changes observed in the pancreas during differentiation process may also be dependent on sequential alteration in transcription factors [25-31]. The highest co-expression of Ngn3, Pdx 1 and NeuroD with insulin at early stage of endocrine cell lineage in PDL pancreas is in agreement with many studies [2,10,32-34]. However, this study further enlightens previous suggestion that duct ligated pancreatic tissues obtained at $84 \mathrm{~h}$ post PDL and used for transplantation yielded $50 \%$ success rate [17]. We therefore propose an early transplantation using $12-24 \mathrm{~h}$ post PDL harvested pancreatic tissues. This suggestion has not been reported in literature.

\subsection{Implications and perspectives of the study}

The present data on beta cell development and co-expression of insulin with caspase3, Pdx1, Ngn3, NeuroD and pax6 will have implications in the pathophysiology of the pancreas, such as diabetes mellitus management.

\subsection{Strength and limitations of the study}

The present study may be limited to some degree, despite its strength from rigourous methodology. Its strength resides in the use of pre- and post PDL tissues preserved in Bouin's fluid for immunohistofluorescent study not commonly used elsewhere; and which may also be its first limitation.

The second limitation was the lack of optimization and method controls omitted in the materials and methods, which could have helped in reducing some false positive results of gene expression. This might well serve to explain the higher variability (systematic error or bias in measurement) of gene expression at critical times.

The strength of the study is based on the use of the expression pattern of transcription factors and the definition of the time-related efficiency of the expression of each protein profile according to the sequence of cellular lineage after PDL. This approach helped to categorize the present result in morphological changes as landmarks for each target protein expression.

While this study reinforces the observation from the literature [35] that showed that the activation of beta cell progenitors and increased beta cell mass in adult mice pancreas following ductal ligation, it is important highlight some limitations regarding total caspase 3 expression and sophisticated and expensive techniques.

Total caspase 3 expression is not generally an accepted measure of cell death. The lack of cleaved caspase 3 and/or TUNEL staining markers of both necrosis and apoptosis, forced us to use total caspase 2 expression to evaluate beta-cell death.

Beta cell proliferation was not evaluated using Ki67, PCNA or $\mathrm{PH} 3$ expression.

Co-expression of glucagon plus insulin was not quantified in this study, this be performed in future as extreme beta cell loss results in conversion of adult pancreatic alpha-cells to beta-cells [36]. 


\section{Conclusion}

These findings indicate that the optimal efficiency of co-expression of insulin with each one of the assessed homeodomain proteins occur between $12 \mathrm{~h}$ and $24 \mathrm{~h}$ after PDL. We therefore propose an early islets transplantation, using $12-24 \mathrm{~h}$ post PDL harvested pancreatic tissues.

\section{Financial disclosure}

This study received the support of the MRC grant, and the WSU institutional grant.

\section{References}

[1] Schwitzgebel VM, Scheel DW, Conners JR, Kalamaras J, Lee JE, Anderson DJ, et al.. Expression of neurogenin3 reveals an islet cell precursor population in the pancreas. Development 2000;127:3533-42.

[2] Schwitzgebel VM. Programming of the pancreas. Mol Cell Endocrinol 2001;185:99-108.

[3] Slack JMW. Developmental biology of the pancreas. Development 1995;121:1569-80.

[4] Sander M, Neubusser A, Kalamaras J, Ee HC, Martin GR, German MS. Genetic analysis reveals that PAX6 is required for normal transcription of pancreatic hormone genes and islet development. Genes Dev 1997;11:1662-73.

[5] Gittes GK, Rutter WJ. Onset of cell-specific gene expression in the developing mouse pancreas. Proc Natl Acad Sci USA 1992;89:1128-32.

[6] Upchurch BH, Aponte GW, Leiter AB. Expression of peptide YY in all four islet cell types in the developing mouse pancreas suggests a common peptide YY-producing progenitor. Development 1994;120:245-52.

[7] Lee JC, Smith SB, Watada H, Lin J, Scheel DW, Wang J, et al.. Regulation of the pro-endocrine gene neurogenin3. Diabetes 2001;50:928-36.

[8] Sommers L, Ma Q, Anderson DJ. Neurogenins, a novel family of atonal-related bHLH transcription factors, are putative mammalian neuronal determination genes that reveal progenitor cell heterogeneity in the developing CNS and PNS. Mol Cell Neurosci 1996;8:221-41.

[9] Huang H-P, Liu M, El-hodiri HM, Chu K, Jamrich M, Tsai M-J. Regulation of the pancreatic islet-specific gene BETA2 (neuroD) by neurogenin 3. Mol Cell Biol 2000;20:3292-307.

[10] Gradwolhl G, Dierich A, Lemeur M, Guillemot F. Neurogenin3 is required for the development of the four endocrine cell lineages of the pancreas. Proc Natl Acad Sci USA 2000;97:1607-11.

[11] Sosa-pineda B, Chowdhury K, Torres M, Oliver G, Gruss P. The Pax4 gene is essential for differentiation of insulin-producing beta cells in the mammalian pancreas. Nature 1997;386:399-402.

[12] Smith S, Ee H, Conners C, German M. Paired-homeodomain transcription factor PAX4 acts as a transcriptional repressor in early pancreatic development. Mol Cell Biol 1999;19:8272-80.

[13] IDF. A consensus statement from the International Diabetes Federation. Diabet Med 2006;23:469-80.

[14] Longo-Mbenza B, Kasiam Lasi On'kin JB, Nge Okwe A, Kangola kabangu N, Mbungu Fuele S. Metabolic syndromes, aging, physical inactivity, and incidences of type 2 diabetes in general African population. Diab Vasc Dis Res 2010;7:28-39.

[15] Bliss M. In: McClelland, Stewart, editors. The discovery of insulin. Chicago: University of Chicago; 1982.
[16] Vincent S. Chapter on the pancreas. In: Read books. Internal secretion and the ductless gland; 2007. p. 39-50. ISBN: $1408624842,9781408624845$.

[17] Page BJ, du Toit DF, Muller CJ, Mattysen J, Lyners R. Autogenous transplantation of a duct ligated pancreas: a functional and histological study. J Pancreas 2004;5:71-80.

[18] Peshevaria M, Gamer L, Henderson E, Teitelan G, Wright CVE, Stein R. X1Hbox8, an endoderm-specific xenopus homeodomain protein, is closely related to a mammalian insulin gene transcription factor. Mol Endocrinol 1994;8:806-16.

[19] Stoffers DA, Thomas MK, Habner JF. Homeodomain protein IDX-1: a master regulator of pancreas development and insulin gene expression. Trends Endocrinol Metab 1997;8:145-51.

[20] Pictet R, Rutter WJ. Development of the embryonic endocrine pancreas. Washington, DC: American Physiological Society; 1972.

[21] Pang K, Mukonoweshuro C, Wong G. Beta cells arise from glucose transporter type 2 (Glut2)-expressing epithelial cells of the developing rat pancreas. Proc Natl Acad Sci USA 1994;91:9559-63.

[22] Oster A, Jensen J, Serup P, Galante P, Madsen OD, Larsson LI. Rat endocrine pancreatic development in relation to two homebox gene products (Pdx-1 and Nkx 6.1). J Histochem Cytochem 1998;46:707-15.

[23] St-onge L, Sosa-Pineda B, Chowdhury K, Mansouri A, Gruss P. Pax6 is required for differentiation of glucagon-producing alpha cells in mouse pancreas. Nature 1997;387:406-9.

[24] Dohrmann C, Gruss P, Lemaire L. Pax genes and the differentiation of hormone-producing endocrine cells in the pancreas. Mech Dev 2000;92:47-54.

[25] Collombat P, Hecksher-Sorensen J, Serup P, Mansouri A. Specifying pancreatic endocrine cell fates. Mech Dev 2006;123:501-12.

[26] Sander M, German MS. The beta cell transcription factors and development of the pancreas. J Mol Med 1997;75:327-40.

[27] Stoffers DA, Thomas MK, Habner JF. Homeodomain protein IDX-1: a master regulator of pancreas development and insulin gene expression. Trends Endocrinol Metab 1999;8:145-51.

[28] Kim SK, Mac Donald RJ. Signalling and transcriptional control of pancreatic organogenesis. Curr Opin Genes Dev 2002;12:540-7.

[29] Jensen J. Gene regulatory in pancreatic development. Dev Dyn 2004;229:176-200.

[30] Servitja JM, Ferrer J. Transcription networks controlling pancreatic development of beta cell function. Diabetology 2004:47:597-613.

[31] Lyttle BM, Li J, Krishnamurthy M, Fellows F, Wheeler MB, Goodyer CG, et al.. Transcription factor expression in the developing human fetal endocrine pancreas. Diabetology 2008;51:1169-80.

[32] Naya FJ, Stellrecht CM, Tsai MJ. Tissue specific regulation of the insulin gene by a novel basic helix-loop-helix transcription factor. Genes Dev 1995;9:1009-19.

[33] Collombat P, Hecksher-Sorensen J, Serup P, Mansouri A. Specifying pancreatic endocrine cell fates. Mech Dev 2006;123:501-12.

[34] Johansson KA, Dursun U, Jordan N, Gu G, Beermann F, Gradwohl G, et al.. Temporal control of neurogenin3 activity in pancreas progenitors reveals competence windows for the generation of different endocrine cell types. Dev Cell 2007;12:457-65.

[35] Xu X, D’Hoker J, Stangé G, Bonné S, De Leu N, Xiao X, et al.. cells can be generated from endogenous progenitors in injured adult mouse pancreas. Cell 2008;132:183-4.

[36] Thorel F, Népote V, Avril I, Kohno K, Desgraz R, Chera S, et al.. Conversion of adult pancreatic $\alpha$-cells to $\beta$-cells after extreme $\beta$-cell loss. Nature 2010;464:1149-54. 